\title{
Uncertainty in hourly mean data from classical magnetometers
}

\author{
J. J. Curto* ${ }^{*}$
}

\begin{abstract}
Hourly mean values obtained from analog magnetometers in what can be considered the "classical" period constitute the largest quantity of data we have on the evolution of the Earth's magnetic field. They are used for a wide variety of applications such as estimating long-term solar-terrestrial interactions, the production of magnetic indices, or studying geomagnetic secular variation originated in the Earth's core. However, these data do not have an associated uncertainty that would allow us to quantify the final uncertainty of the results of these models. Hence, our study tries to assess the degree of uncertainty that these data actually have. In this paper, using Ebro Observatory classical instrumentation, we work out these uncertainties by estimating the particular uncertainties of each significant variable involved in the measuring procedure. Although the study is implemented for Ebro, the method can be applied to any other observatory. We found that, in general, uncertainties vary from one magnetic component to another, depending on the nature of the instruments that were used. In each component, we identified the weakest points where the biggest part of the error resides. With our results we can state that total uncertainties ranged from 1 to $4 \mathrm{nT}$.
\end{abstract}

Keywords: Uncertainties, Classical magnetometers, Hourly means

\section{Introduction}

The advent of magnetic observatories during the ninetieth century as a way to observe the geomagnetic field daily led to the creation of a database of terrestrial magnetism which is stored in the World Data Centers. What this database has given us are the hourly mean values of the three main magnetic components $(D, H, Z)$. These historical data, collected using magnets and photographic paper records during decades, make up the largest body of data on the evolution of the geomagnetic field, with more data and information than the set of digital data collected from the 1980s onward. These historical data are of great value for modelers due to this uniqueness. They are used for a wide variety of applications, including estimating long-term solar-terrestrial interactions, the production of magnetic indices for monitoring the Earth's magnetosphere and ionosphere, mapping electric currents in the

\footnotetext{
*Correspondence: jjcurto@obsebre.es

Observatorio del Ebro, (OE) CSIC - Universitat Ramon Llull, Roquetes, Spain
}

Earth's ionosphere, exploring the electrical conductivity of the Earth's mantle, or for studying geomagnetic secular variation originating in the Earth's core (Hrvoic and Newitt 2011). However, we do not have an associated uncertainty for these data that would allow us to quantify the final uncertainty of the results of the models. For this reason, our study tries to assess the degree of uncertainty that these data have. Having said that, uncertainties in hourly means due to the lack of some minute data because of instrument failure, calibrations, or manmade magnetic noise (spikes, the occasional presence of iron in the neighborhood, etc.) have already been dealt with by Marsal and Curto (2009) and will not be considered in this paper.

Instruments to measure the Earth's magnetic field at magnetic observatories have been placed into two categories over the years: those that measured the temporal changes in the field on a continual basis without taking into account the absolute accuracy of the observation (variometers), and those instruments that measured the absolute value of the magnetic field at a specific instant in time (absolute magnetometers). For almost a century, 
photographic variometers were the primary instruments for recording temporal fluctuations in the magnetic field and a wide variety of instruments have been used to measure the absolute value of the magnetic field like for example induction magnetometers, QHM (Quartz horizontal magnetometer), BMZ (Balance magnétométrique zéro) and declinometers. Towards the end of the twentieth century, a plethora of new magnetometers incorporating electronic technology with greater thermal and mechanical stability gradually replaced the classical ones. Thus, nowadays, in modern magnetic observatories, the most widely used instruments for recording magnetic field variations include the tri-axial fluxgate magnetometer, while for absolute observations, the declinationinclination magnetometer, in conjunction with a proton precession or an Overhauser magnetometer, are the most common instruments (Matzka et al. 2010).

The Observatori de l'Ebre (Ebro Observatory, OE) is a research institute with over a 100 years of history. It was founded by the religious order, the Society of Jesus, in 1904 to study Sun-Earth relationships. The Observatory has collected geomagnetic records for more than 100 years (Merveille 1908). Gathering these data began in 1910, and has continued ever since except for the period from April 1938 to December 1941. The data were collected in an analog format until 2000 and have been gathered digitally since then. However, many of the twentieth century records of the three magnetic field elements have now also been digitized using a system developed at the Ebro Observatory itself (Curto et al. 1996).

In the following sections we will give a brief description of the basic functioning of the classical magnetometers (absolute and variometers) used at the Ebro Observatory as an example of what the majority of the magnetic observatories had available in the twentieth century to measure the Earth's magnetic field. Afterwards, we will explain the processes used to calculate the hourly means with each instrument and finally we will carry out the aforementioned uncertainty computations.

\section{Absolute measurements}

Absolute measurements are made using absolute or semi-absolute instruments to achieve the required absolute accuracy. In the "classical" era (until the end of the twentieth century), several instruments were used to measure the absolute value of the magnetic field. Figure 1 presents those used at the Ebro Observatory. In the middle of the twentieth century, La Cour designed magnetometers came into being and rapidly became the most commonly used ones because of their reliability and easy handling. Most of the magnetic observatories, including Ebro, opted for them. They became the standard

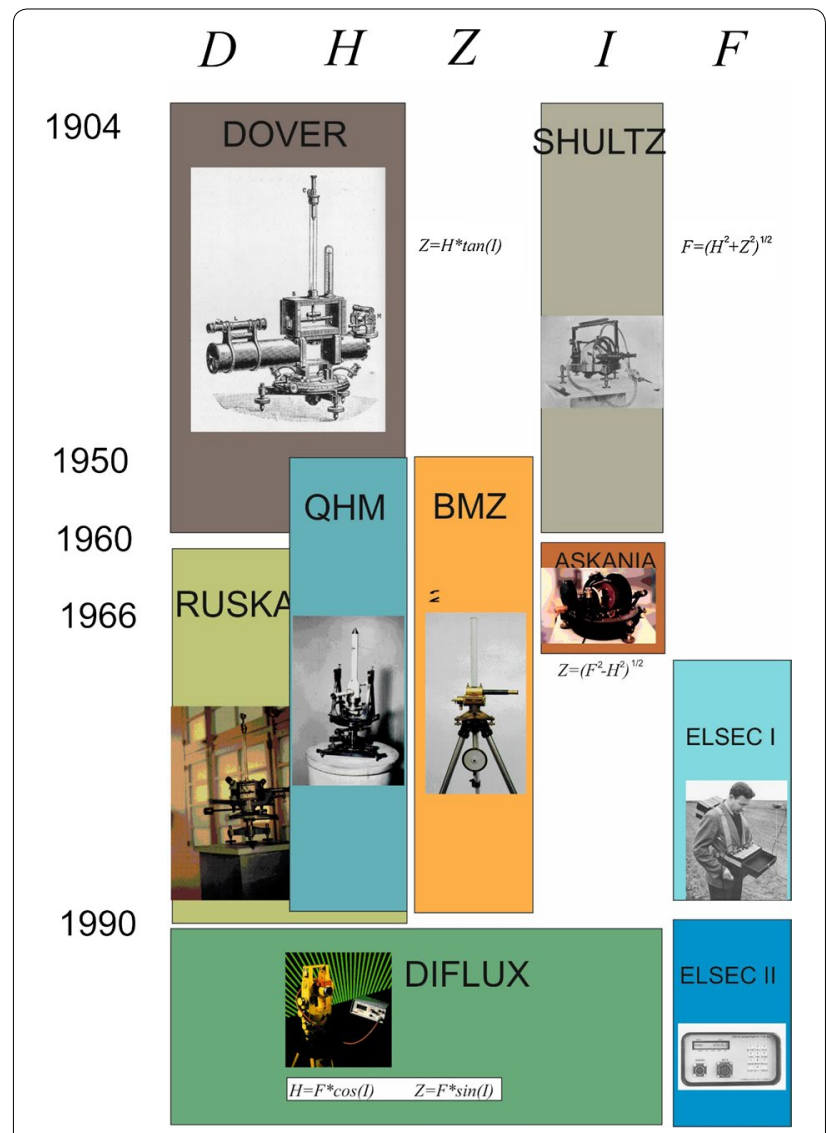

Fig. 1 Chronogram of the absolute instruments used at Ebro Observatory during the twentieth century

instruments for the second half of the century, a period that can be considered as the "golden age" of classical magnetometers.

First of all, we will describe the bases and the operational procedures of the main instruments used at Ebro.

\section{Declinometer}

A classical declinometer was used to measure declination, $D$ (Lauridsen 1981) (Fig. 2).

A magnet was hung from a very thin and long fiber for a low torque and a mirror was stuck parallel to the magnet axis. A torque, $\tau$, in the static case when the magnetic field was unchanging, aligned the magnet (with magnetic moment $M$ ) with the Earth's magnetic field, $B$, and so

$$
\tau=M \times B .
$$

The suspended magnet was placed on top of a nonmagnetic theodolite making it possible to observe the magnet's mirror through a telescope joined to the theodolite. The theodolite was then turned until the telescope was aligned perpendicular to the mirror. The direction of 


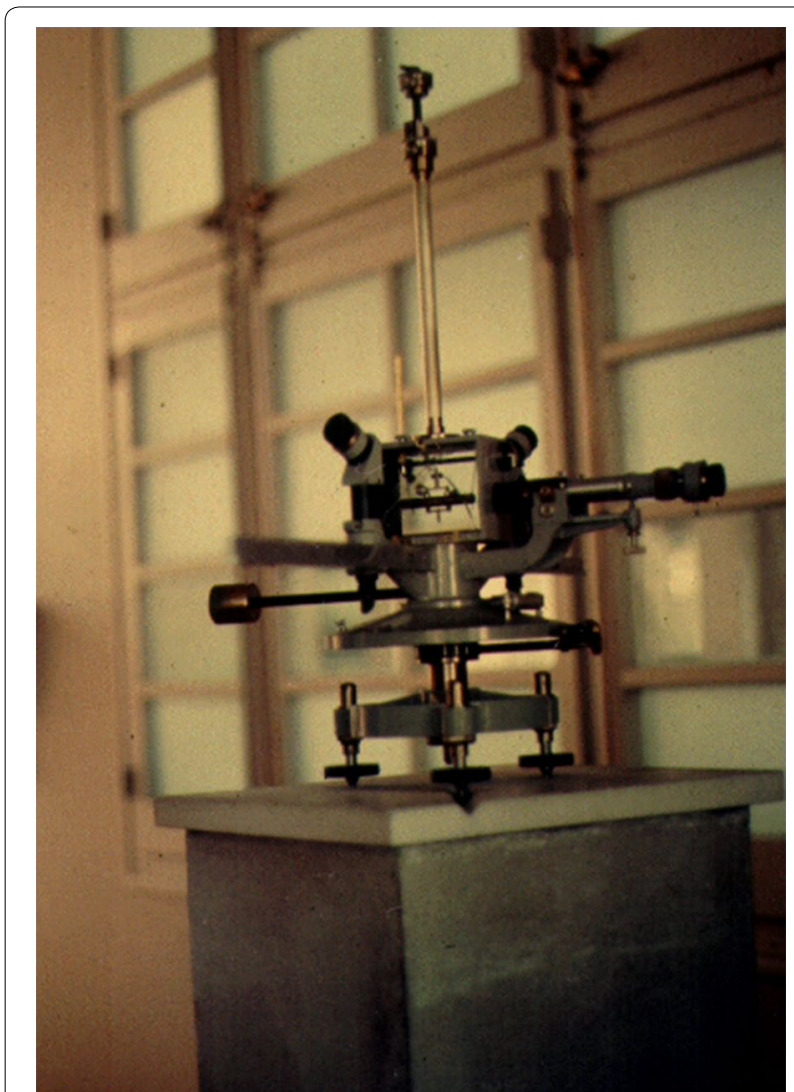

Fig. 2 Declinometer RUSKA at Ebro Observatory

the magnetic meridian, $A$, was then read from the theodolite's base (Fig. 3). Next, the reference mark was sighted and the angle, $B$, was read from the theodolite's base. Knowing the true bearing of the reference mark $\left(A_{z}\right)$, the magnetic declination could be calculated:

$$
D_{a b s}=A-\left(B-A_{z}\right) .
$$

In fact, the $A$ and $B$ angles were measured several times and a mean was taken (Fig. 4).

Declinometers were also used to measure horizontal intensity using the classical method of oscillations and deflections developed by Gauss (Wienert 1970). However, this method was long and tedious and was soon replaced by more direct measurements using a QHM.

\section{Quartz horizontal magnetometer QHM}

Soon after its appearance, the Quartz horizontal magnetometer (QHM) became the most commonly used instrument for measuring the horizontal intensity of the magnetic field. The QHM was a compact tube-like instrument consisting of a small magnet with a mirror, suspended on a quartz fiber, and mounted on a non-magnetic

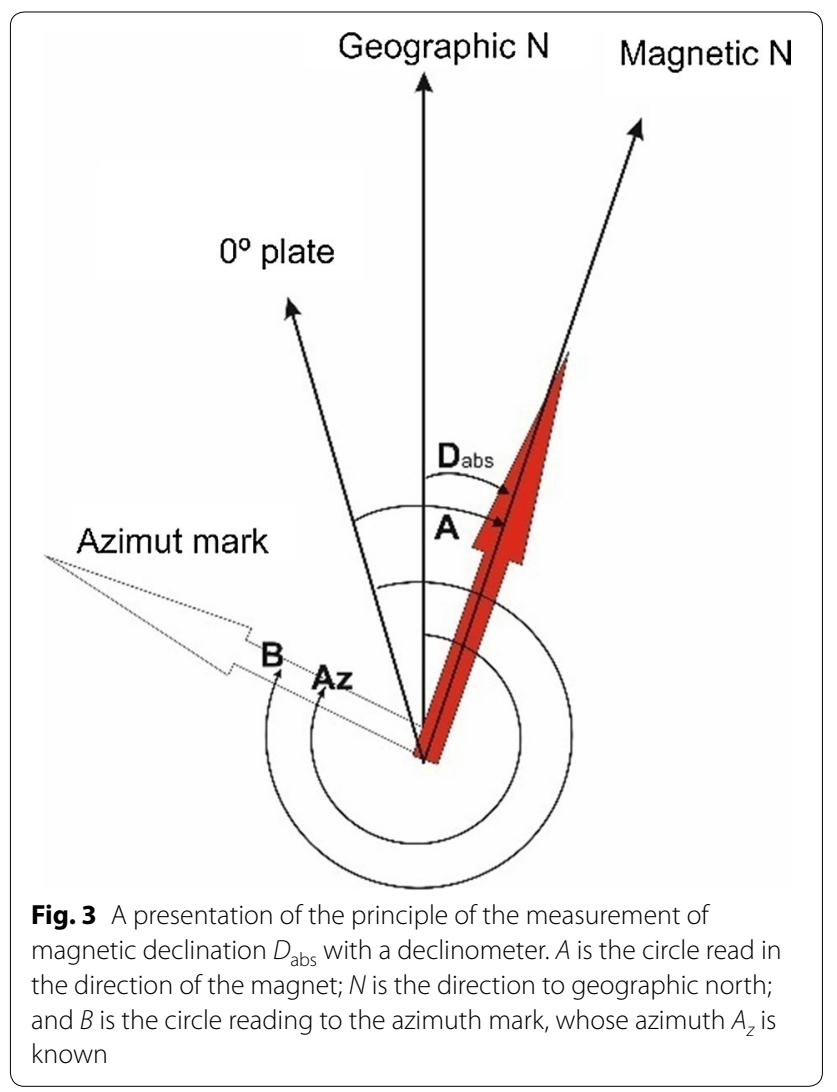

theodolite (La Cour 1936). Unlike the declinometers, this quartz fiber had to have an appreciable torque. A telescope was fitted onto an opening in the tube (Fig. 5).

To take a measurement, the theodolite was turned a complete number of half-turns, such that the magnet was moved away from the magnetic meridian position, $A_{o}$, by an angle of at least $45^{\circ}, A_{+}$. The angle was recorded and then the theodolite was rotated in the opposite direction, $A_{-}$(Fig. 6). $H_{\text {abs }}$ was then calculated from the following formula (Jankowski and Sucksdorff 1996):

$$
H_{\mathrm{abs}}=\frac{C}{\left(1-k_{1} t_{\mathrm{abs}}\right)} *\left(1+k_{2} \mathcal{H} \cos \varphi\right) * \sin \varphi,
$$

where $\varphi=\left(\mathrm{A}_{+}-\mathrm{A}_{-}\right) / 2$ and $C=2 \pi \tau / M . \tau$ is the torsion constant of the quartz fiber and $M$ is the magnetic moment of the magnet. $C$ was determined experimentally by comparison observations. The temperature dependence of $C$ was given by the first term in the denominator; $k_{1}$ is the temperature coefficient and $t_{\mathrm{abs}}$ is the temperature when making the absolute measurement. The other term gives the effect of induction on the magnet. Here $\mathcal{H}$ refers to an approximate value of the horizontal magnetic field component, so the annual mean was used. This was a recommended practice because units (and tens) of nT 


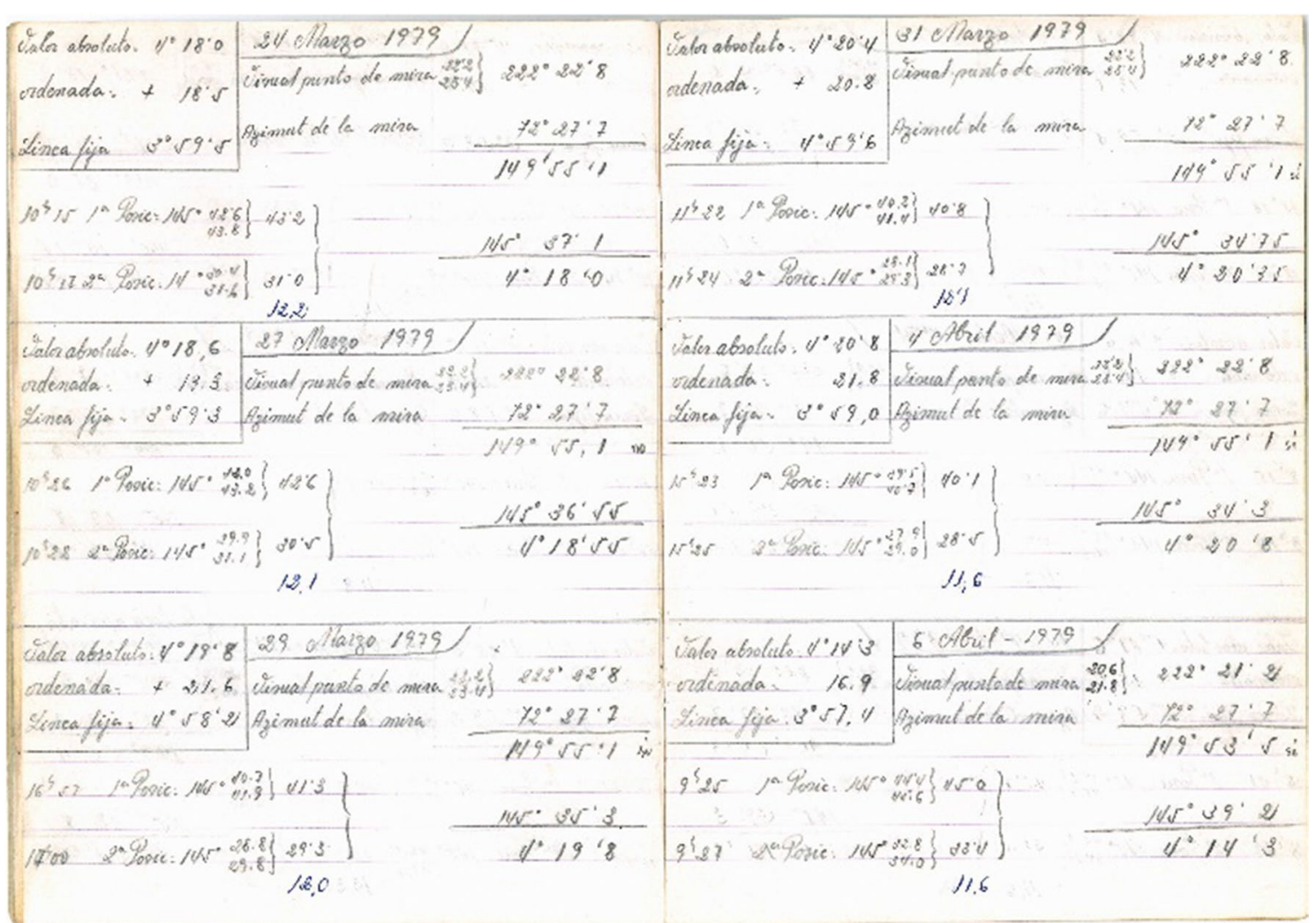

Fig. 4 Copy of a fragment of a notebook with annotated measures from the declinometer at Ebro Observatory

in this variable did not affect the value of the term due to the small value of $k_{2}$. This is because a high level of accuracy was not necessary since $k_{2}$ was very small. Both $k_{1}$ and $k_{2}$ were determined experimentally. The influence of $\alpha$ angles is waived by taking the two measurements $\mathrm{A}_{+}$ and $\mathrm{A}_{-}$(they cancel each other out). In addition, the $\alpha$ angle is made small by the manufacturer of the instrument so the simplified formula 3 can be used.

The three constants $\left(C, k_{1}\right.$, and $\left.k_{2}\right)$ changed slowly with time, so the QHM could not be considered per se a true absolute instrument. However, in fact, $k_{1}$ and $k_{2}$ could be considered as constants for about 10 years; and $C$ had to be re-determined only after about 2 or 3 years (Wienert 1970). A set of calibrated QHM were air freighted in order to obtain comparisons between observatories. Effects from aging of the fibers could be approximated by linear inter- and extrapolation of the calibration constants (Lauridsen 1977). Figure 7 shows the evolution of the differences between the $H$ values computed with the original constants and those after the respective international comparisons. The best fit indicates a variation greater than $1 \mathrm{nT}$ per year.

The arrival of the DIflux magnetometer in the 1990s allowed us to check the performance of classical magnetometers against this new absolute standard. In particular, the QHM corrected with international comparisons matched very well with the values produced by DIflux.

\section{Measurement of $Z$ with the field balance}

The measurement of the $Z$ component was usually carried out with a field balance, BMZ (Fig. 8).This instrument was designed by La Cour (1942) and used as a relative instrument for the measurement of the vertical component. It consisted of a horizontal magnet resting on knife edges, $k$ (Fig. 9). This magnet $(B)$ moved in the magnetic prime vertical (in the magnetic meridional plane). Therefore, the horizontal intensity had no influence on the scale values. It had a zero indicator (freely moving horizontal magnet), and three magnets which compensated the vertical component of the field (Fig. 8). Two of these magnets ( $C$ and $S$ ) were vertical and fixed while the other one $(T)$, called the turn magnet, could be rotated and was mounted on a graduated disc. The BMZ is a null instrument. The measurement is achieved when magnet $B$ is completely horizontal so the sum of the magnetic field produced by magnets $C, T$ and $S$ compensates the vertical component of the natural field. The moment 


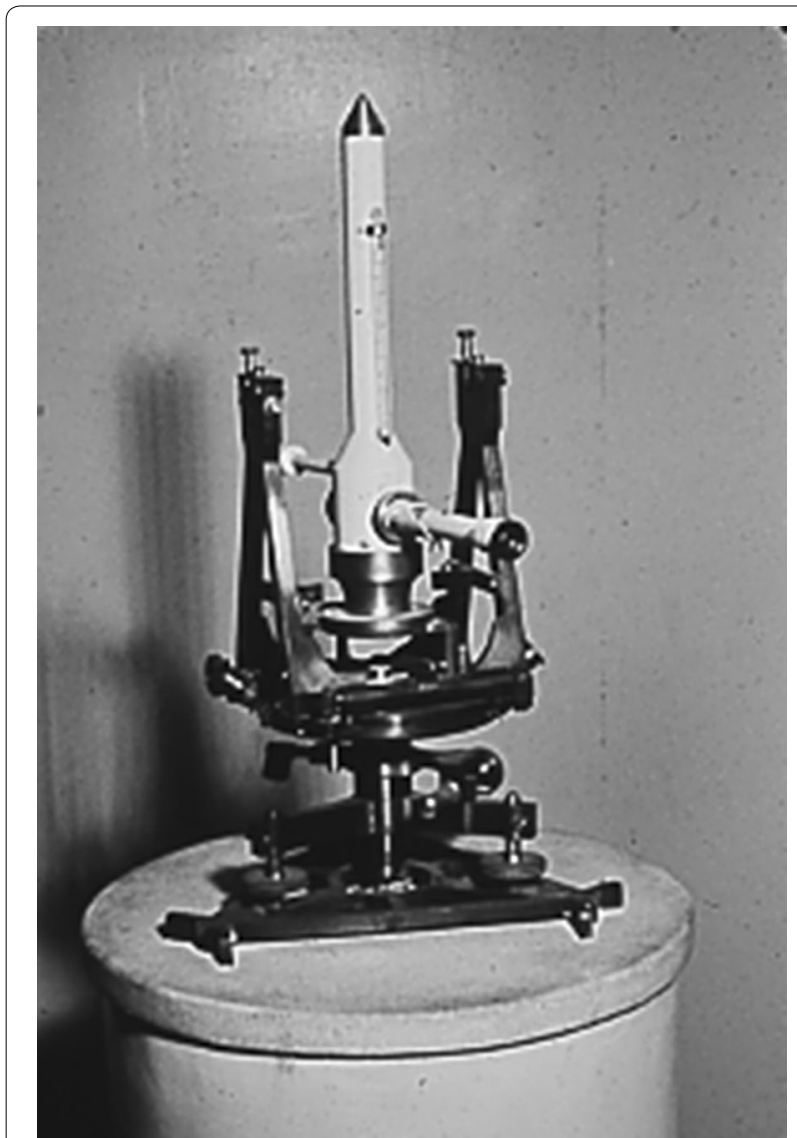

Fig. 5 QHM at Ebro Observatory

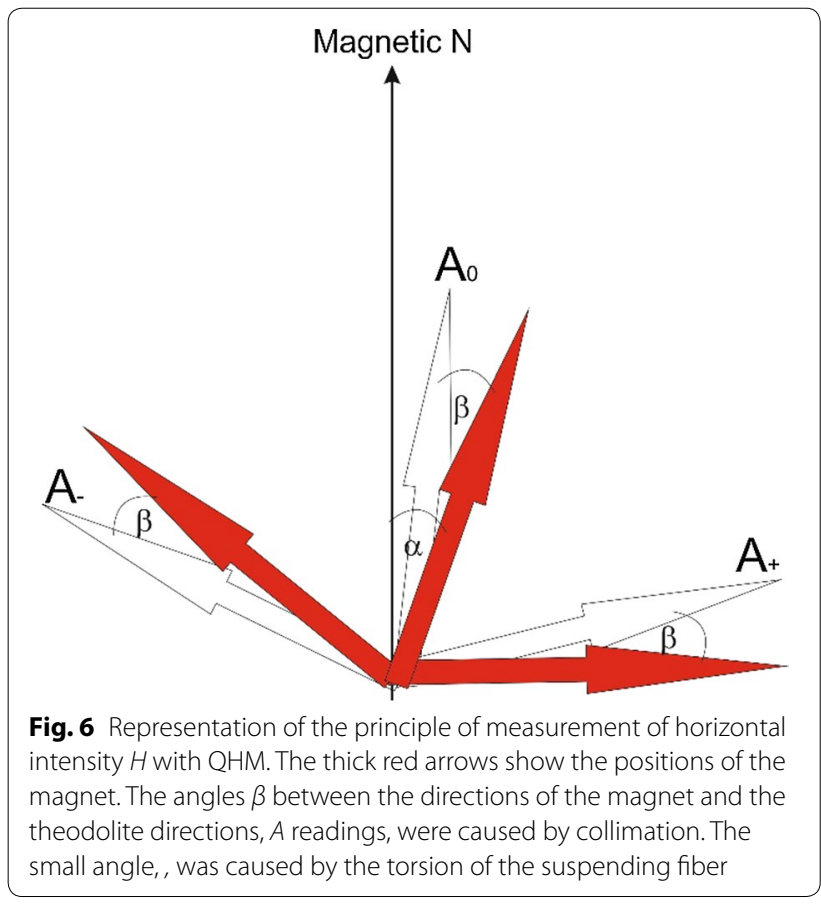

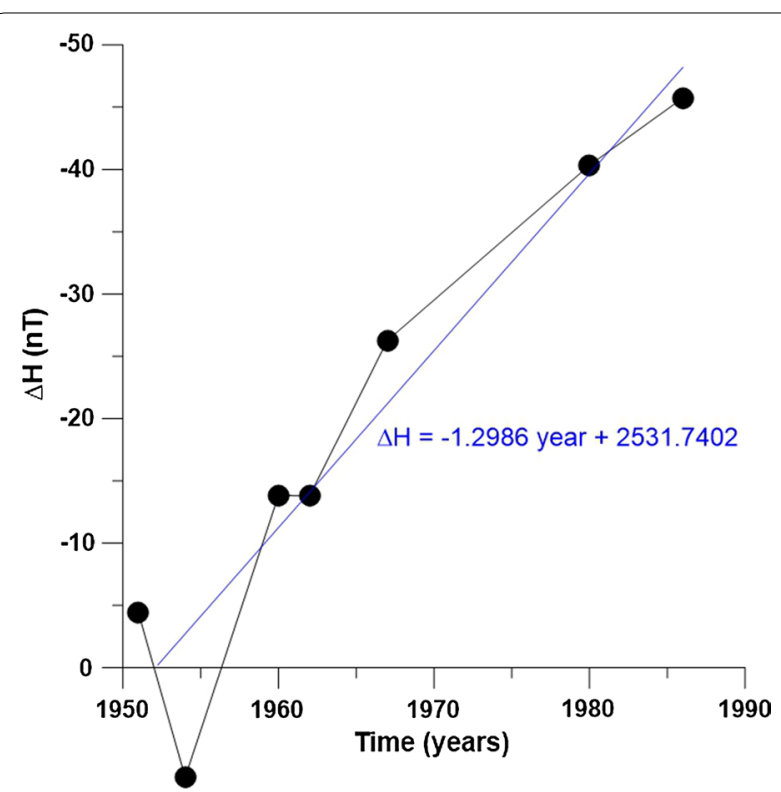

Fig. 7 Temporal evolution of the differences between $H$ values at Ebro computed with the original coefficients and those corrected after the international comparisons. Black dots point out the moments when the calibrated QHM visited Ebro. The blue line is the best fit

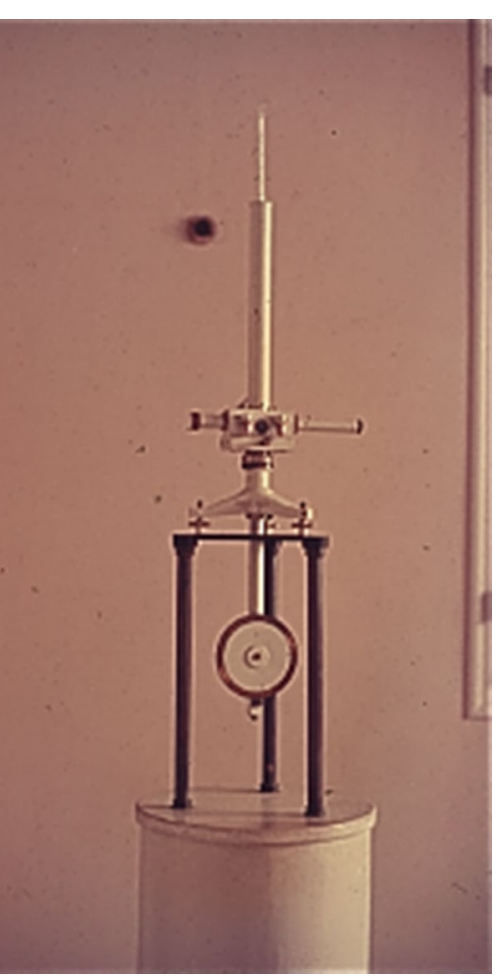

Fig. 8 BMZ at Ebro Observatory 


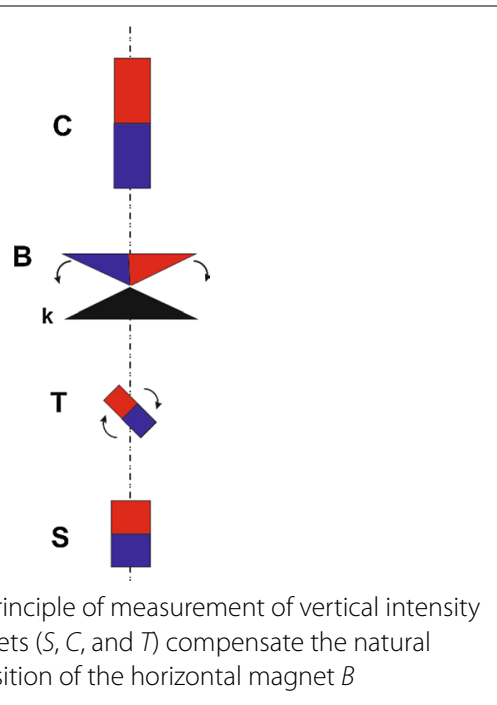

of magnet $B$ is not relevant. Magnets $C$ and $S$ are fixed while the fine adjustment is performed by rotating magnet $T$. Maximum intensity is achieved when the longitudinal axis of $T$ is vertical and the minimum intensity occurs when it is horizontal.

The vertical magnetic component could be estimated as:

$$
Z_{\mathrm{abs}}=Z_{c}+Z_{s}+Z_{T}-a t_{\mathrm{abs}}-2 a \Delta t,
$$

where $Z_{\text {abs }}$ is the vertical intensity of the Earth's magnetic field at the moment of the measurement; $Z_{c}$ is the field of the compensating magnet, $C$, at the center of the balance magnet, $B$, at $0{ }^{\circ} \mathrm{C} ; Z_{s}$ is the field of the supplementary magnet, $S$, at the center of the balance magnet at $0{ }^{\circ} \mathrm{C} ; Z_{T}$ is the field of the turn magnet, $T$, at the center of the balance magnet at $0{ }^{\circ} \mathrm{C}$

The magnetic moment of the magnets counteracting the natural field vary this temperature and therefore their contribution to the additional magnetic field. The manufacturer assessed this variation and gave the value of this temperature coefficient $(\alpha)$ proposing to compute the variation in two specific terms related to temperature $t_{\mathrm{abs}}$ (in degrees centigrade) and the change of temperature during the whole process of measurement, $\Delta t_{\mathrm{abs}}$. This last term was of second order and was usually disregarded. The manufacturer also gave the value of $Z_{C}+Z_{S}$ and the $Z_{T}$ for disc readings.

Unlike the QHM, the BMZ required careful leveling. The field balance had a poor long-term stability.

\section{Variometers}

Variometers are magnetometers which are used to record continuously the time variations of the magnetic field. For more than 10 years, torsional magnetometers with suspended or balanced magnets were used at nearly all

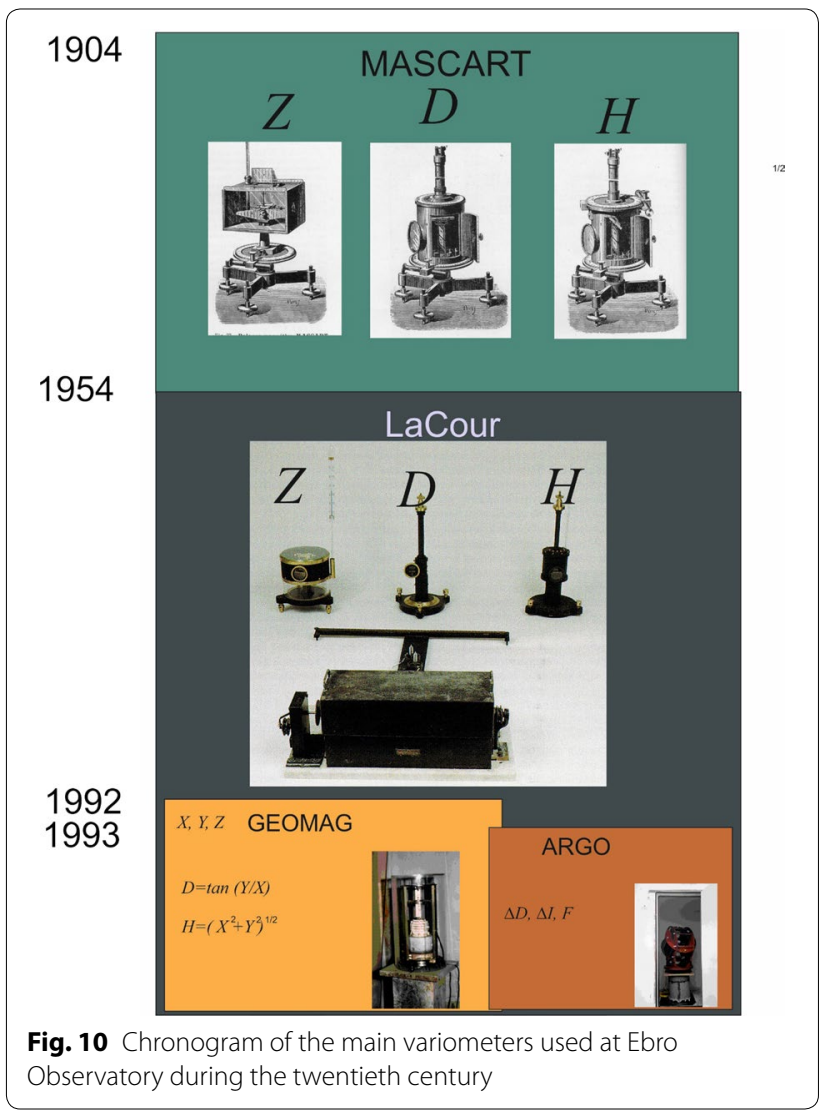

the magnetic observatories in the world for continuous recordings of the field variations. Figure 10 presents a representation of those used at the Ebro Observatory.

The variations were recorded on photographic paper (Wienert 1970; Laursen and Olsen 1971). In a classical variometer system, like the one designed by La Cour (1930) (Fig. 11), a light beam went from a lamp through a diaphragm to the variometer mirror, and reflected back from there focusing on the rotating drum where it formed a clear spot.

Photographic paper was wrapped around the drum. The spot of light drew the magnetogram on the moving photographic paper. Another light beam reflected from a fixed mirror drew a straight line on the photographic paper, and produced the base-line of the magnetogram (Fig. 12). All three components were usually recorded on the same magnetogram. The drum was driven uniformly by a clockwork mechanism, doing one revolution per day. So, each day the band containing the daily record of the magnetic field of the preceding day was removed from the drum (and replaced by a new one), developed and measured. The time stamp was produced by a relay system that turned off the beam light producing the traces for a while. The main clock driving this signal was corrected daily by radio signals from an atomic clock. We 


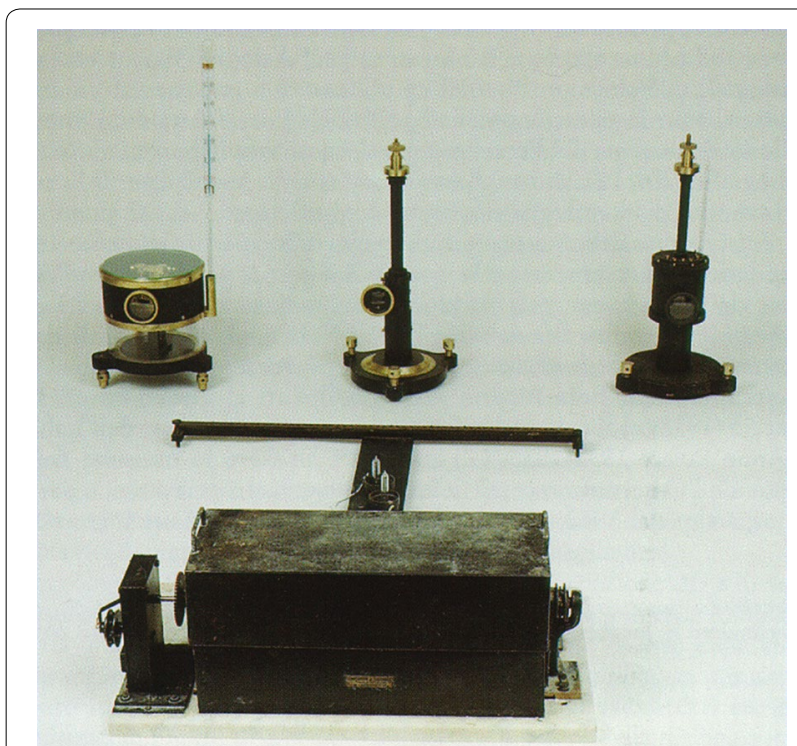

Fig. 11 LaCour magnetograph: in the background, the $Z$ (left), $D$ (center) and $H$ (right) sensors, and in the foreground, the case with the photographic drum for making the recording. Notice the clockwork motor on the left-hand side

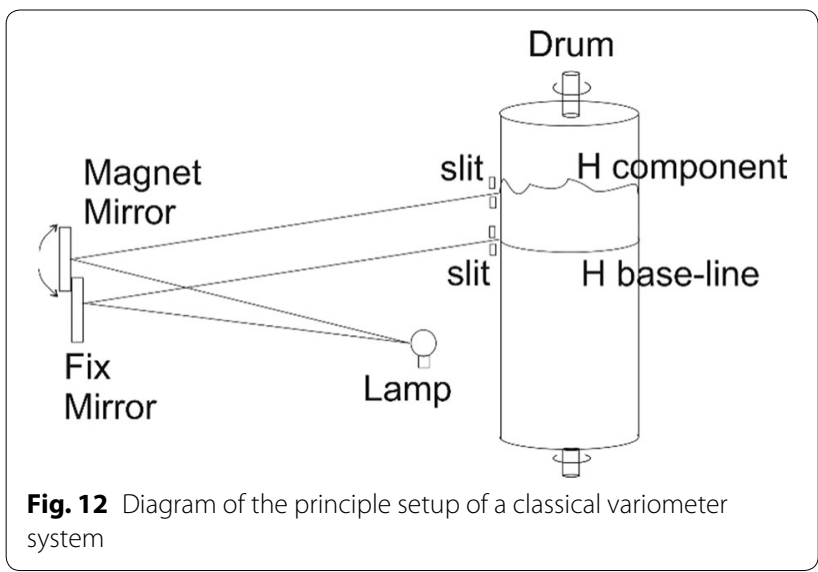

estimate the delay in the commutation to be tenths of seconds, so we consider there is no incidence in the minute values.

The initial position of each trace of the components on the paper was rather arbitrary and operators attempted to keep them closer to their fixed base-line and to leave them far enough apart to prevent them crossing each other. Figure 13 shows a copy of a real analog recording. There were some problems in the measurement due to the partial loss of traces or the different thickness of them as can be appreciated (Curto et al. 1996).

The traces of the three components were spaced to leave room for the diurnal variation $(\mathrm{Sq})$ as well as for disturbed times (SD). In Table 1, we provide the annual mean values of these variations for the Ebro Observatory. These data are relevant because they condition the position of the traces on the magnetogram and, at the same time, condition the desirable scale values of the observatory.

In some observatories, the temperature trace was also included in the magnetogram as another component.

\section{Routine observations: base-line values and scale value determinations Base-line values}

The base-line value is the value which has to be added to the data produced by the variometer to obtain the final absolute values of the magnetic field component. They were obtained by smoothing the results of the absolute measurements over a period of several weeks. Spikes and other artificial effects had to be removed. And special care was taken in detecting jumps from the normal trend which were tested to see if they were real changes in the base-line. The desired situation was for magnetometers to be stable enough so the base-line values would change slowly.

Absolute observations for the determination of the base line values $\left(D_{0}, H_{o}\right.$, and $\left.Z_{o}\right)$ were usually made once every 1 or 2 weeks. Normally these observations were made on the same day of each week, unless a magnetic storm was in progress. In this case, the observations were postponed until the disturbance had abated. At the same time as each absolute measurement was being taken, $t_{\mathrm{abs}}$, the ordinates on the magnetogram were determined ( $\left.n_{\text {Dabs }}, n_{H \text { abs }}, n_{Z \text { abs }}\right)$. The ordinates were the result of the measurement of the distance between the position of the fixed light spot (base-line) and the variable light spot (magnetic component) on the magnetogram at that moment.

The sensitivity of the variometers to the magnetic field was measured by the scale values. They were essential to compute the base lines, and represented the amount of displacement in the magnetograms when a unitary variation of the magnetic field was applied. They depended on the angular movement of the mirrors stuck on the magnets and also on the distance between the sensors and the recording case. They were adjusted in such a way that even big excursions of the light spot still fitted on the magnetogram during episodes of agitation in the course of magnetic storms.

Scale-value determinations $\left(S_{D}, S_{H}\right.$, and $\left.S_{Z}\right)$ were carried out at the same rate as the absolute measurements. To do this, an additional magnetic field was created using Helmholtz-Gaugin coils while a precision milli-ammeter connected in series with the coils controlled the current of the coils. By measuring the deflection on the traces as a consequence of the applied field, scale values were calculated. 


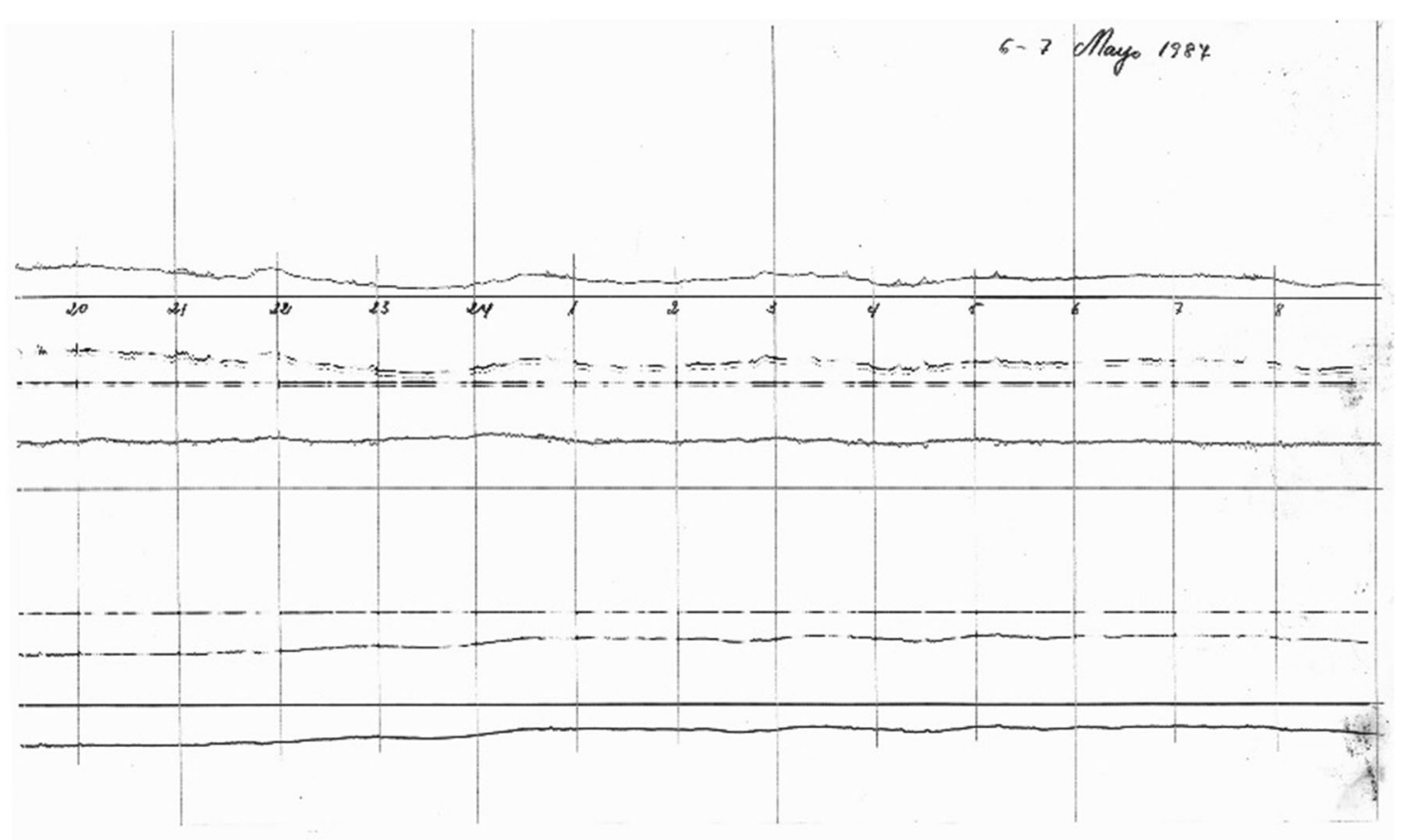

Fig. 13 Copy of a fragment of a magnetogram from the Ebro Observatory corresponding to the end of 6 May, 1987, and the beginning of the next day (7 May, 1987)

Table 1 Amplitude of the diurnal variation for quiet (Sq) and disturbed (SD) days at Ebro Observatory and their equivalence in displacement on the magnetograms

\begin{tabular}{lllll}
\hline & Sq (nT) & Sq $(\mathbf{m m})$ & SD $(\mathbf{n T})$ & SD $(\mathbf{m m})$ \\
\hline Delta $X(\mathrm{nT})$ & 10 & 2.22 & 35 & 7.77 \\
Delta $Y(\mathrm{nT})$ & 45 & 6.25 & 45 & 6.25 \\
Delta $Z(\mathrm{nT})$ & 20 & 2.29 & 20 & 2.29 \\
\hline
\end{tabular}

\section{Data processing: base lines and hourly means} Preparation of the base-line values graph

The amount of labor involved in data processing was lower when the temperature of the variometer room was constant, with little or no daily variation or only slow dayby-day changes (as at the Ebro Observatory where variometers were confined in a cave). Base-line values could be obtained as:

$$
\begin{aligned}
& D_{0}=D_{\mathrm{abs}}-S_{D} n_{D \mathrm{abs}}, \\
& H_{0}=H_{\mathrm{abs}}-S_{H} n_{H \mathrm{abs}}, \\
& Z_{0}=Z_{\mathrm{abs}}-S_{Z} n_{Z \mathrm{abs}},
\end{aligned}
$$

where 0 , sub-index stands for base-line values and abs, for absolute measurements. $S$ are the scale values and, $n$, the ordinates. In this case, the base line values showed only a small variation over the course of the year. If the intensity variometers had small temperature coefficients, the temperature correction could be done by drawing them on a single sheet of graph paper together with the scale values. The base-line values were usually scattered because of errors in absolute observations and instability in the variometers. It was common to draw a smooth line through the cloud of points representing the base-line values, which was then approximated by a step function using small steps (Fig. 14). In cases when the base line values of any of the components changed abruptly, the change was evenly distributed over the interval between the two measurements. The base line values obtained by stepping the smooth line were called 'adopted base-line values' and were used for working out the hourly means.

\section{Hourly means}

The production of hourly data was labor-intensive work, with direct measurements taken on the magnetograms. Each magnetogram had to be measured under conditions of approximately the same relative humidity and temperature as they had been recorded so as to ensure the stability of the dimensions of the photographic paper. A glass plate with an engraved scale was used for scaling instantaneous ordinates $\left(n_{\text {Dabs }}, n_{H \text { abs }}, n_{Z \text { abs }}\right)$ (Fig. 15a). Grid lines on the 


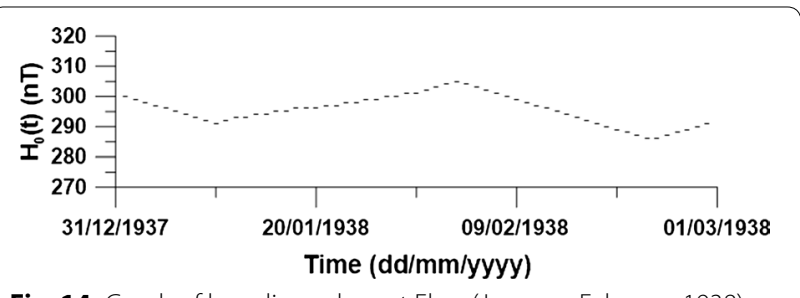

Fig. 14 Graph of base line values at Ebro (January-February 1938)

glass scale were $0.1 \mathrm{~mm}$ thick. The same plate was used for scaling the ordinates of hourly means $\left(n_{D m}, n_{H m}, n_{Z m}\right)$ (Fig. 15b). In this case, the vertical scale was located parallel to the time axis while a horizontal line was set for the average ordinate of the trace between two adjacent hour marks. The objective was to have the same number of squares above (red) and below (green) the horizontal line.

Since the traces of the components and the base lines had a certain width, the centers of the lines were used.

At the Ebro Observatory a "high" temporal development was used and so $1 \mathrm{~h}$ was displayed as $30 \mathrm{~mm}$ in the magnetogram. Counting squares of $1 \mathrm{~mm}^{2}$ with the scaled glass was equivalent to taking 1 measurement every $2 \min =30$ samples per hour.

The scaled hourly means of the ordinates were converted from millimeters into minutes of arc ( $D$ component) or nanoTeslas ( $H$ and $Z$ component) by means of the respective scale values (Fig. 16). The computation of hourly means can be obtained with the following equations:

$$
D_{m}=D_{o}+S_{D} \cdot n_{D m}
$$

$$
\begin{aligned}
& H_{m}=H_{o}+S_{H} \cdot n_{H m}-q_{H}\left(T_{m}-T_{s}\right), \\
& Z_{m}=Z_{o}+S_{Z} \cdot n_{Z m}-q_{Z}\left(T_{m}-T_{s}\right),
\end{aligned}
$$

where $D_{o}, H_{o}$ and $Z_{o}$ were the determined base-line values for that hour, $S_{D}, S_{H}$ and $S_{Z}$ were the scale values, $n_{D m}, n_{H m}$ and $n_{Z m}$ the mean of the ordinates at that hour in millimeters, $q_{H}$ and $q_{Z}$ the temperature coefficients of the intensity variometers, and with $T_{m}$ being the actual temperature and $T_{s}$ the standard temperature when the variometer was calibrated.

$D$ was not temperature dependent because, even though the magnetic moment changed with temperature, the magnet always pointed north. In most cases, the temperature of the variometer room changed slowly. As pointed out previously, at the Ebro Observatory, variometers were kept in a thermally isolated cave to reduce daily humidity and temperature changes. The day to day variation was less than $0.1{ }^{\circ} \mathrm{C}$. The residual temperature coefficients of the intensity variometers were small and so a common practice was to add the temperature corrections to the base line values instead of correcting the ordinates, which saved time and labor:

$$
\begin{aligned}
& H_{m}=H_{o}^{\prime}+S_{H} \cdot n_{H m}, \\
& Z_{m}=Z_{o}^{\prime}+S_{Z} \cdot n_{Z m} .
\end{aligned}
$$

Most of these data were computed manually or with the help of a simple calculator. Double checking was a common practice to ensure monthly tables in bulletins were free from errors (Fig. 17). a

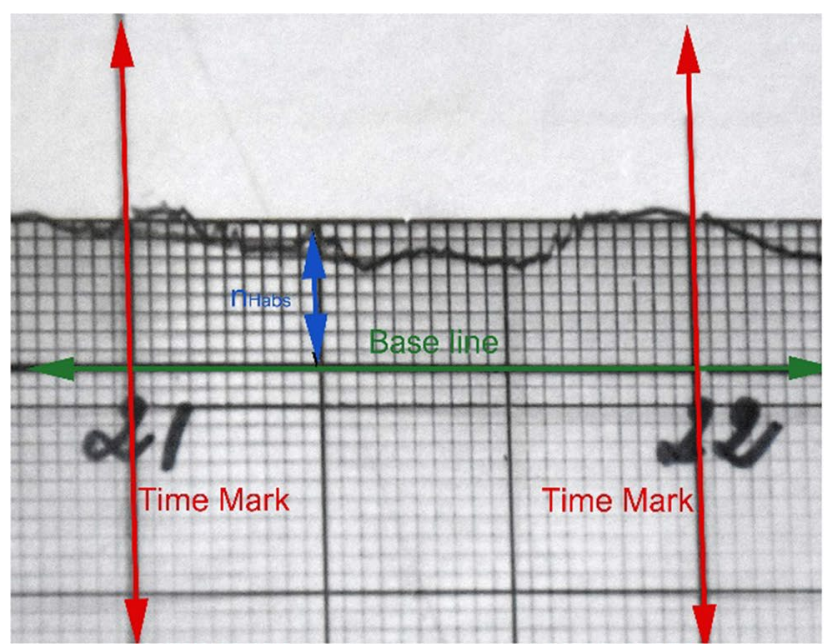

b

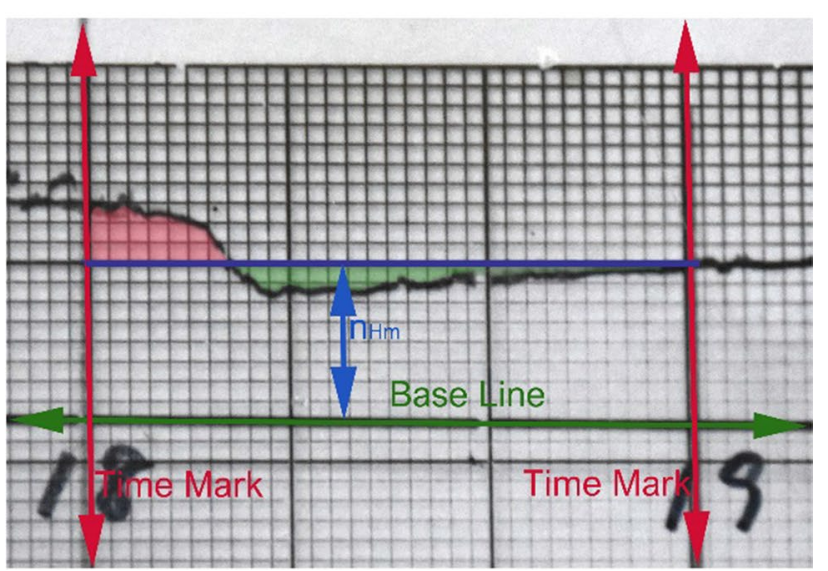

Fig. 15 Measurement of ordinates by means of a glass scale. a Scale adjusted for measuring the ordinate at a discrete time (21 h $19 \mathrm{~min}, 7.9 \mathrm{~mm}) . \mathbf{b}$ Scale adjusted for measuring the hourly mean (18-19 h, $8.1 \mathrm{~mm}$ ) 


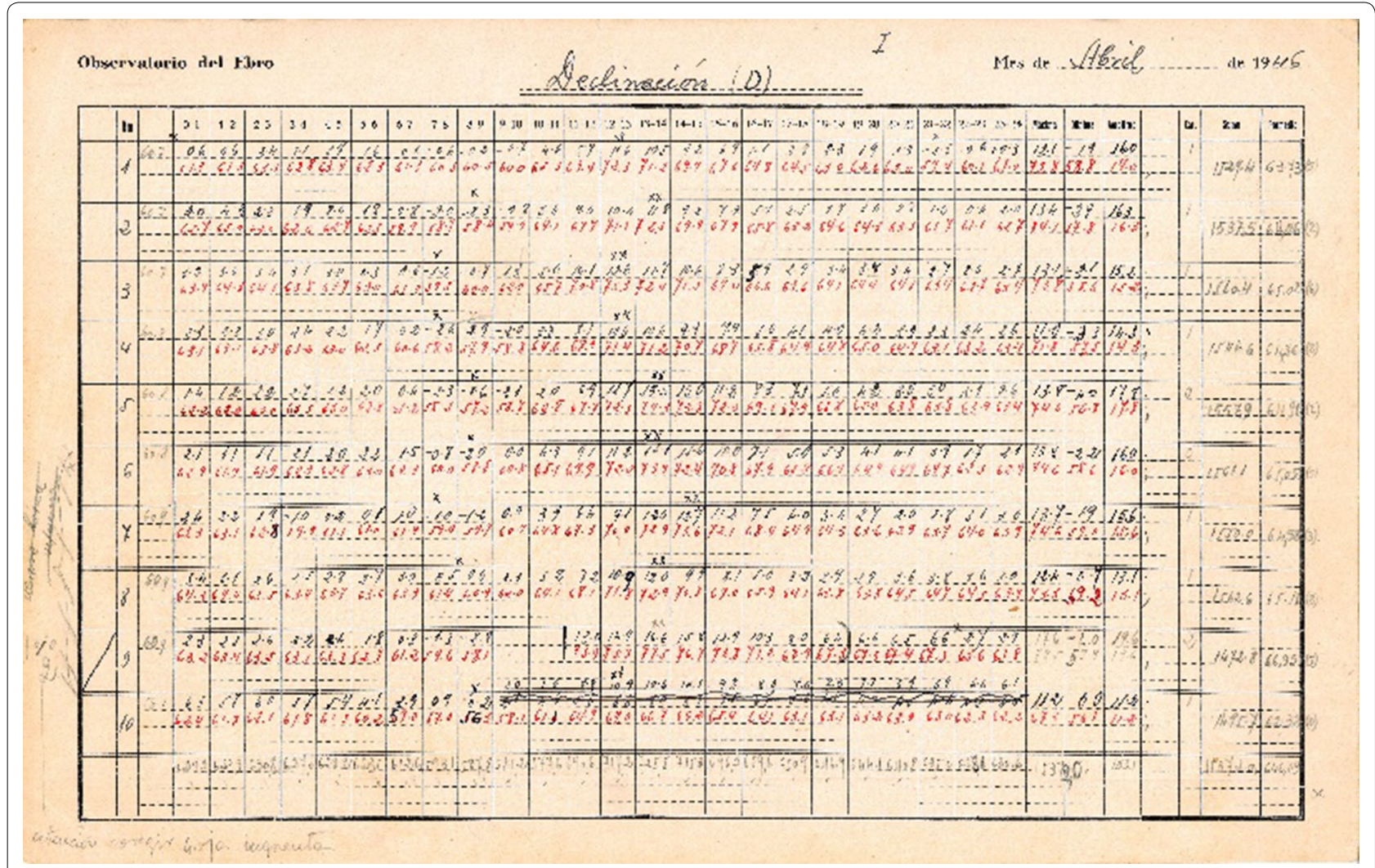

Fig. 16 Copy of the table sheet with the conversion from mm into minutes of arc for Ebro D component in April 1946

\section{Uncertainties calculation}

For the $D$ component, and summarizing the basic formulas displayed in the previous chapter

$$
\begin{aligned}
& D_{\mathrm{abs}}=A-\left(B-A_{Z}\right), \\
& D_{0}=D_{\mathrm{abs}}-S_{D} n_{D \mathrm{abs}} .
\end{aligned}
$$

Thus, we can express the hourly mean as:

$$
D_{m}=D_{0}+S_{D} n_{D m}=A-\left(B-A_{Z}\right)+S_{D}\left(n_{D m}-n_{D \mathrm{abs}}\right) .
$$

So, uncertainties can be computed deriving the whole expression as regards each variable involved in the relationship:

$$
\begin{aligned}
\delta D_{m}^{2}= & \left(\frac{\partial D_{m}}{\partial A} \delta A\right)^{2}+\left(\frac{\partial D_{m}}{\partial B} \delta B\right)^{2}+\left(\frac{\partial D_{m}}{\partial A_{Z}} \delta A_{Z}\right)^{2} \\
& +\left(\frac{\partial D_{m}}{\partial S_{D}} \delta S_{D}\right)^{2}+\left(\frac{\partial D_{m}}{\partial n_{D m}} \delta n_{D m}\right)^{2}+\left(\frac{\partial D_{m}}{\partial n_{D \mathrm{abs}}} \delta n_{D \mathrm{abs}}\right)^{2} \\
= & (\delta A)^{2}+(\delta B)^{2}+\left(\delta A_{Z}\right)^{2}+\left(\left(n_{D m}-n_{D \mathrm{abs}}\right) \delta S_{D}\right)^{2} \\
& +\left(S_{D} \delta n_{D m}\right)^{2}+\left(S_{D} \delta n_{D \mathrm{abs}}\right)^{2} .
\end{aligned}
$$

Table 2 presents the values of each variable and each term of the previous formula. The uncertainty of a variable is mainly related to the resolution it is measured with (Hogan 2017). The total uncertainty for $D$ component is about $0.6 \mathrm{~min}$ of arc which could be translated directly into $4 \mathrm{nT}$ (in Ebro $\Delta Y \approx \Delta D^{*} 7 \mathrm{nT} / \mathrm{min}$ ). The first three rows account for uncertainties due to the absolute measurements while the last three rows account for uncertainties due to the variometer. The term with biggest weight was the one related to the scale value.

In the notebooks, $A, B$, and $A_{z}$ were given in degrees and minutes. In our table, we only used minutes so as to work with a single set of units.

Moving the sensor (with the reflecting mirror) back and forth, observers managed to have a separation between the mirror and the band such that $S_{D}=1.0$ which made the conversion of $\mathrm{mm}$ into minutes of arc easier and avoided tedious computations.

It was complex to determine $A$ in practice because there were some sources of error. First, it is nearly impossible to attach a mirror at exactly $90^{\circ}$ to the magnetic axis of the magnet, and secondly, a truly torsion-less fiber does not exist. Thus, to minimize these errors, carrying out a real observation with the declinometer involved taking several 


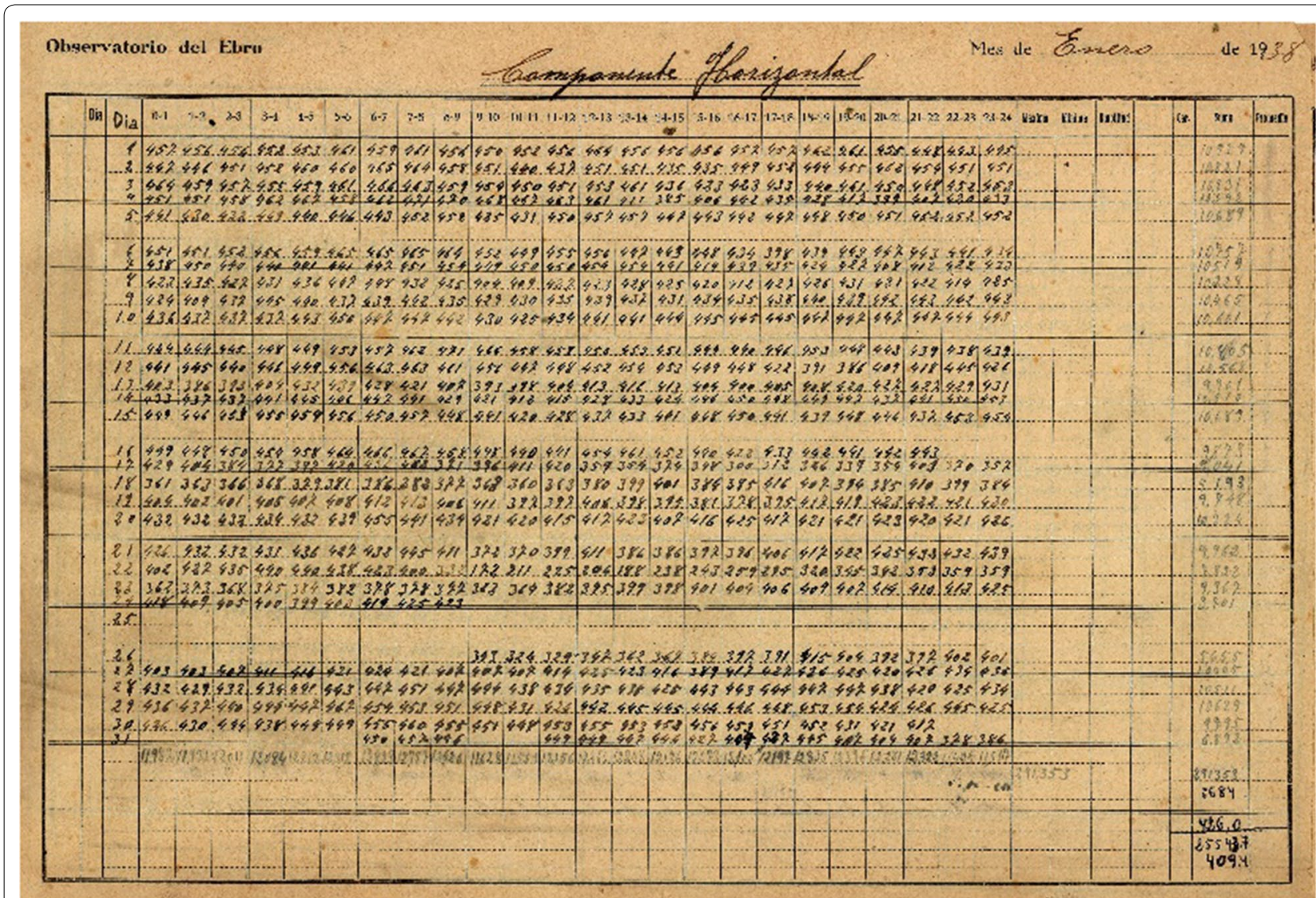

Fig. 17 Copy of the table sheet with the final values of $H$ component for Ebro D component in January 1938

Table 2 Uncertainties for $D$ component

\begin{tabular}{lclll}
\hline Variable & Value of the variable & $\begin{array}{l}\text { Uncertainty }(\boldsymbol{\delta}) \\
\text { of the variable }\end{array}$ & Term & $\begin{array}{c}\text { Uncertainty } \\
\text { of the term }\end{array}$ \\
\hline$A\left(^{\prime}\right)$ & 8737.1 & 0.05 & $(\delta A)^{2}$ & 0.0025 \\
$B\left(^{\prime}\right)$ & $13,342.8$ & 0.1 & $(\delta B)^{2}$ & 0.01 \\
$A_{z}\left({ }^{\prime}\right)$ & 4347.7 & 0.1 & $\left(\delta A_{Z}\right)^{2}$ & 0.01 \\
$S_{D}\left({ }^{\prime} / \mathrm{mm}\right)$ & 1.0 & 0.1 & $\left(\left(n_{D m}-n_{D \text { Dabs }}\right) \delta S_{D}\right)^{2}$ & 0.390625 \\
$n_{\text {Dabs }}(\mathrm{mm})$ & 18.5 & 0.1 & $\left(S_{D} \delta n_{D m}\right)^{2}$ & 0.01 \\
$n_{D m}(\mathrm{~mm})$ & 24.75 & 0.12 & $\left(S_{D} \delta n_{\text {Dabs }}\right)^{2}$ & 0.0144 \\
& & & Total uncertainty $D_{m}\left({ }^{\prime}\right)$ & 0.6 \\
\hline
\end{tabular}

The dominant term is emphasized in italics

angular observations with the magnet in both upward, $G_{\text {up }}$, and downward positions, $G_{\text {down }}$. The measurements were repeated with another magnet so additional $G^{\prime}$ up and $G^{\prime}{ }_{\text {down }}$ angles complemented the data set:

$$
A=\left(G_{\text {up }}+G_{\text {down }}+G_{\text {up }}^{\prime}+G_{\text {down }}^{\prime}\right) / 4 \text {, }
$$

$$
\begin{aligned}
\delta A & =\sqrt{\left(\frac{\delta G_{\mathrm{up}}}{4}\right)^{2}+\left(\frac{\delta G_{\text {down }}}{4}\right)^{2}+\left(\frac{\delta G_{\mathrm{up}}^{\prime}}{4}\right)^{2}+\left(\frac{\delta G_{\text {down }}^{\prime}}{4}\right)^{2}} \\
& =\frac{\delta G}{\sqrt{4}}=\frac{\delta G}{2}
\end{aligned}
$$


where we assume the four individual determinations have the same amount of error, $G$. These errors are in quadrature (ISO 1993; Taylor 1982).

On the other hand, with the procedure used to obtain the hourly mean that has been explained before, we assumed, in practice, $2 \mathrm{~mm}^{2}$ as the maximum error in squares counting for an hour (30 temporal steps). Thus, we estimated $\delta n_{D m}$ as $\sqrt{0.1^{2}+\left(\frac{2}{30}\right)^{2}}=0.12$, where 0.1 is the error in the measurement of the base-line and

$$
\begin{aligned}
H_{m}= & H_{0}^{\prime}+S_{H} n_{H m}=C /\left(1-k_{1} t_{\mathrm{abs}}\right) *\left(1+k_{2} \mathcal{H} \cos \varphi\right) \\
& * \sin \varphi+S_{H}\left(n_{H m}-n_{H \mathrm{abs}}\right) \\
\approx & C *\left(1+k_{1} t_{\mathrm{abs}}\right) *\left(1+k_{2} \mathcal{H} \cos \varphi\right) * \sin \varphi \\
& +S_{H}\left(n_{H m}-n_{H \mathrm{abs}}\right) .
\end{aligned}
$$

Again, uncertainties can be computed deriving the whole expression as regards each variable involved in the relationship:

$$
\begin{aligned}
\delta H_{m}^{2}= & \left(\frac{\partial H_{m}}{\partial C} \delta C\right)^{2}+\left(\frac{\partial H_{m}}{\partial k_{1}} \delta k_{1}\right)^{2}+\left(\frac{\partial H_{m}}{\partial t_{\mathrm{abs}}} \delta t_{\mathrm{abs}}\right)^{2}+\left(\frac{\partial H_{m}}{\partial k_{2}} \delta k_{2}\right)^{2}+\left(\frac{\partial H_{m}}{\partial \mathcal{H}} \delta \mathcal{H}\right)^{2}+\left(\frac{\partial H_{m}}{\partial \varphi} \delta \varphi\right)^{2} \\
& +\left(\frac{\partial H_{m}}{\partial S_{H}} \delta S_{H}\right)^{2}+\left(\frac{\partial H_{m}}{\partial n_{H m}} \delta n_{H m}\right)^{2}+\left(\frac{\partial H_{m}}{\partial n_{H \mathrm{abs}}} \delta n_{H \mathrm{abs}}\right)^{2} \\
= & \left.\left.\left(\left(1+k_{1} t_{\mathrm{abs}}\right) *\left(1+k_{2} \mathcal{H} \cos \varphi\right) * \sin \varphi\right) \delta C\right)^{2}+\left(C *\left(t_{\mathrm{abs}}\right) *\left(1+k_{2} \mathcal{H} \cos \varphi\right) * \sin \varphi\right) \delta k_{1}\right)^{2} \\
& \left.\left.+\left(C *\left(k_{1}\right) *\left(1+k_{2} \mathcal{H} \cos \varphi\right) * \sin \varphi\right) \delta t_{\mathrm{abs}}\right)^{2}+\left(C *\left(1+k_{1} t_{\mathrm{abs}}\right) *(\mathcal{H} \cos \varphi) * \sin \varphi\right) \delta k_{2}\right)^{2} \\
& \left.+\left(C *\left(1+k_{1} t_{\mathrm{abs}}\right) *\left(k_{2} \cos \varphi\right) * \sin \varphi\right) \delta \mathcal{H}\right)^{2}+\left(C *\left(1+k_{1} t_{\mathrm{abs}}\right) *\left(\cos \varphi\left(1+k_{2} \cos \varphi\right)-k_{2} \mathcal{H} \sin ^{2} \varphi\right) \delta \varphi\right)^{2} \\
& +\left(\left(n_{H m}-n_{H \mathrm{abs}}\right) \delta S_{H}\right)^{2}+\left(S_{H} \delta n_{H m}\right)^{2}+\left(S_{H} \delta n_{H \mathrm{abs}}\right)^{2} .
\end{aligned}
$$

$(2 / 30)$ is the error for the mean itself. Again, both errors are in quadrature.

\section{For the $\mathrm{H}$ component, the basic formulas were}

$$
\begin{aligned}
& H_{\mathrm{abs}}=\frac{C}{\left(1-k_{1} t_{\mathrm{abs}}\right)} *\left(1+k_{2} \mathcal{H} \cos \varphi\right) * \sin \varphi, \\
& H_{0}^{\prime}=H_{\mathrm{abs}}-S_{H} n_{H \mathrm{abs}},
\end{aligned}
$$

which allow us to compute the hourly mean as:
Table 3 presents the values of each variable and each term of the previous formula. The total uncertainty for this component is about $1 \mathrm{nT}$. The main term producing uncertainty is the one which refers to the variometer, especially regarding scale value which, in turn, depends on the relative variations of the magnetic field between the two times $t_{\text {abs }}$ and $t_{m}$.

At Ebro Observatory, a real observation with QHM involved taking up to four different observations with the theodolite, firstly turned left and then turned right

\section{Table 3 Uncertainties for $\boldsymbol{H}$ component}

\begin{tabular}{lllll}
\hline Variable & Value of the variable & $\begin{array}{l}\text { Uncertainty }(\boldsymbol{\delta}) \\
\text { of the variable }\end{array}$ & Term & $\begin{array}{c}\text { Uncertainty } \\
\text { of the term }\end{array}$ \\
\hline $\mathrm{C}(\mathrm{nT})$ & 9023.2 & 0.1 & $\left.\left(\left(1+k_{1} t_{\mathrm{abs}}\right) *\left(1+k_{2} \mathcal{H} \cos \varphi\right) * \sin \varphi\right) \delta C\right)^{2}$ & 0.07432742 \\
$k_{1}\left({ }^{\circ} \mathrm{C}^{-1}\right)$ & 0.000476 & $1.00 \mathrm{E}-06$ & $\left.\left(C *\left(t_{\mathrm{abs}}\right) *\left(1+k_{2} \mathcal{H} \cos \varphi\right) * \sin \varphi\right) \delta k_{1}\right)^{2}$ & 0.00892709 \\
$t_{\text {abs }}\left({ }^{\circ} \mathrm{C}\right)$ & 17.46 & 0.1 & $\left.\left(C *\left(k_{1}\right) *\left(1+k_{2} \mathcal{H} \cos \varphi\right) * \sin \varphi\right) \delta t_{\mathrm{abs}}\right)^{2}$ & 0.06630145 \\
$k_{2}\left(\mathrm{nT} T^{-1}\right)$ & $1.18 \mathrm{E}-08$ & $1.00 \mathrm{E}-10$ & $\left.\left(C *\left(1+k_{1} t_{\mathrm{abs}}\right) *(\mathcal{H} \cos \varphi) * \sin \varphi\right) \delta k_{2}\right)^{2}$ & 0.00011531 \\
$\mathcal{H}(\mathrm{nT})$ & 24,600 & 25 & $\left.\left(C *\left(1+k_{1} t_{\mathrm{abs}}\right) *\left(k_{2} \cos \varphi\right) * \sin \varphi\right) \delta \mathcal{H}\right)^{2}$ & $1.6582 \mathrm{E}-06$ \\
$\varphi\left({ }^{\circ}\right)$ & 36.8246 & $1.93925 \mathrm{E}-06$ & $\left(C *\left(1+k_{1} t_{\mathrm{abs}}\right) *\left(\cos \varphi\left(1+k_{2} \cos \varphi\right)-k_{2} \mathcal{H} \sin ^{2} \varphi\right) \delta \varphi\right)^{2}$ & 0.00019951 \\
$S_{H}(\mathrm{nT} / \mathrm{mm})$ & 4.5 & 0.1 & $\left(\left(n_{H m}-n_{\text {Habs }}\right) \delta S_{H}\right)^{2}$ & 0.603729 \\
$n_{\text {Habs }}(\mathrm{mm})$ & 12.7 & 0.1 & $\left(S_{H} \delta n_{H m}\right)^{2}$ & 0.2025 \\
$n_{H m}(\mathrm{~mm})$ & 20.47 & 0.12 & $\left(S_{H} \delta n_{\text {Habs }}\right)^{2}$ & 0.2916 \\
& & & Total uncertainty $H_{m}(\mathrm{nT})$ & 1.1
\end{tabular}




$$
\delta \varphi=\delta A / \sqrt{8}
$$

and $\delta \varphi$ is expressed in radians.

For the $Z$ component, the basic formulas were

$$
\begin{aligned}
& Z_{\mathrm{abs}}=Z_{C}+Z_{S}+Z_{T}-\propto t_{\mathrm{abs}}, \\
& Z_{0}^{\prime}=Z_{\mathrm{abs}}-S_{Z} n_{Z \mathrm{abs}}
\end{aligned}
$$

so the hourly mean computation can be:

$$
\begin{aligned}
Z_{m}= & Z_{0}^{\prime}+S_{Z} n_{Z m}=Z_{C}+Z_{S}+Z_{T} \\
& -\propto t_{\mathrm{abs}}+S_{Z}\left(n_{Z m}-n_{Z \mathrm{abs}}\right) .
\end{aligned}
$$

The uncertainties can be computed deriving the whole expression as regards each variable involved in the relationship:

$$
\begin{aligned}
\delta Z_{m}^{2}= & \left(\frac{\partial Z_{m}}{\partial Z_{C}} \delta Z_{C}\right)^{2}+\left(\frac{\partial Z_{m}}{\partial Z_{S}} \delta Z_{S}\right)^{2}+\left(\frac{\partial Z_{m}}{\partial Z_{T}} \delta Z_{T}\right)^{2}+\left(\frac{\partial Z_{m}}{\partial \alpha} \delta \propto\right)^{2}+\left(\frac{\partial Z_{m}}{\partial t} \delta t\right)^{2}+\left(\frac{\partial Z_{m}}{\partial S_{Z}} \partial \delta\right)^{2} \\
& +\left(\frac{\partial Z_{m}}{\partial n_{Z m}} \delta n_{Z m}\right)^{2}+\left(\frac{\partial Z_{m}}{\partial n_{Z a b s}} \delta n_{Z \text { abs }}\right)^{2}=\left(\delta Z_{C}\right)^{2}+\left(\delta Z_{S}\right)^{2}+\left(\delta Z_{T}\right)^{2}+(t \delta \propto)^{2}+(\propto \delta t)^{2} \\
& +\left(\left(n_{Z m}-n_{Z \text { abs }}\right) \delta S_{Z}\right)^{2}+\left(S_{Z} \delta n_{Z m}\right)^{2}+\left(S_{Z} \delta n_{Z \text { abs }}\right)^{2} .
\end{aligned}
$$

evaluate which parts of the instruments and which practices in an observatory's routine were the main contributors to the final uncertainty in the data. We focused on the period 1950-1990 when instruments developed and constructed by LaCour were used. At that time, these magnetometers became a standard and most of the observatories around the world used them. In fact, they became one of the longest-used and most successful instruments in the history of the geomagnetism.

Our main conclusion is that the uncertainty in the final mean hourly values obtained with classical magnetometers varies from one magnetic component to another. It depends not only on the nature of the absolute measurements, but also on the type of variometer. The uncertainty in the $\mathrm{H}$ component had the lowest value. The dominant term there was that of scale value, but it was not constant because it depended on the amplitude of the diurnal magnetic oscillation regarding the time of the last
Table 4 presents the values of each variable and each term of the previous formula. In the $Z$ component, the total uncertainty is about $3 \mathrm{nT}$. The main term producing uncertainty here is the one referring to absolute measurement, especially due to the high dependence of the magnetic moment of the magnet on temperature.

\section{Conclusions}

We performed the calculation of uncertainties in the hourly mean data collected from classical magnetometers using the Ebro Observatory as a benchmark in order to

Table 4 Uncertainties for $Z$ component

\begin{tabular}{lllll}
\hline Variable & Value of the variable & $\begin{array}{l}\text { Uncertainty }(\boldsymbol{\delta}) \\
\text { of the variable }\end{array}$ & Term & Uncertainty term \\
\hline$Z_{C}+Z_{S}(\mathrm{nT})$ & 36,782 & 1 & $\left(\delta Z_{C}\right)^{2}+\left(\delta Z_{S}\right)^{2}$ & 1 \\
$Z_{T}(\mathrm{nT})$ & 199 & 1 & $\left(\delta Z_{T}\right)^{2}$ & $(t \delta \propto)^{2}$ \\
$\propto\left(\mathrm{nT} /{ }^{\circ} \mathrm{C}\right)$ & 8.3 & 0.1 & $(\propto \delta t)^{2}$ & 3.3124 \\
$t\left({ }^{\circ} \mathrm{C}\right)$ & 18.2 & 0.1 & $\left(\left(n_{Z m}-n_{Z \text { abs }}\right) \delta S_{Z}\right)^{2}$ & 0.6889 \\
$S_{Z}(\mathrm{nT} / \mathrm{mm})$ & 8.7 & 0.1 & $\left(S_{Z} \delta n_{Z m}\right)^{2}$ & 0.052441 \\
$n_{Z \text { abs }}(\mathrm{mm})$ & 12.1 & 0.1 & $\left(S_{Z} \delta n_{Z \text { abs }}\right)^{2}$ & 0.7569 \\
$n_{Z m}(\mathrm{~mm})$ & 14.39 & 0.12 & Total uncertainty $Z_{m}(\mathrm{nT})$ & 1.089936 \\
& & & 2.8
\end{tabular}

calibration.

As regards the $D$ component, although the measurement was very straight forward and had no dependence on the temperature or on the momentum of the magnet, the uncertainty was relatively high because of its poor resolution. Minutes of arc were used as the basic unit but, at Ebro, $1 \mathrm{~min}$ of arc was equivalent to $7 \mathrm{nT}$. Thus, the dominant term was scale value once again.

Finally, the uncertainty in the $Z$ component was moderate. Unlike the other components, here the dominant term was found in the absolute measurement, especially 
due to the high dependence of the magnet momentum on temperature.

In any case, these values were the optimistic ones. Probably, degradation of the instruments (magnet aging together with a lack of regular calibrations, etc.) or a lack of consistency and rigor in the praxis of the observers could have degraded the accuracy of the results.

To conclude, we can state that total uncertainties rank from 1 to $4 \mathrm{nT}$. These values confirm the intuition expressed in the guide for magnetic observatories by Jankowski and Sucksdorff (1996) although we think their claim that at the best observatories absolute accuracy could be better than $1 \mathrm{nT}$ seems, at the least, too optimistic. However, in the same work they admit that at an average observatory with classical equipment, the error could be somewhere between two and three nanoTeslas for an hourly mean. Along these lines, the INTERMAGNET Technical Manual (St. Louis 2011) gave a more realistic figure of $5 \mathrm{nT}$ as a goal for definitive data accuracy, even for a modern observatory.

Without claiming to be exhaustive, the values given here can help to provide an estimate (an order of magnitude) of uncertainties in the output of the modern models that use data from classical magnetometers.

\section{Acknowledgements}

The author acknowledges Santiago Marsal for his help in error formulas and Vincent Lesur who pointed out the necessity to assess the uncertainty of the data from classical magnetometers and helped to improve the paper.

\section{Authors' contributions}

$J J C$ performed the whole analysis and the redaction of the paper. The author read and approved the final manuscript.

\section{Funding}

This research was partially founded by PGC2018-096774-B-I00 (MCIU/AEI/ FEDER, UE) project. We acknowledge support of the publication fee by the CSIC Open Access Publication Support Initiative through its Unit of Information Resources for Research (URICI).

\section{Availability of data and materials}

Historical magnetic data of Ebro Observatory are stored and available through WDC (http://www.wdc.bgs.ac.uk)).

\section{Competing interests}

The authors declare that they have no competing interests.

Received: 30 September 2019 Accepted: 29 November 2019 Published online: 16 December 2019

\section{References}

Curto JJ, Sanclement E, Torta JM (1996) Automatic measurement of magnetic records on photographic paper. Comput Geosci 22:359-368

Hogan R (2017) How to determine resolution uncertainty. Int J Metrol 24-1:20-27

Hrvoic I, Newitt LR (2011) Instruments and methodologies for measurement of the Earth's magnetic field. In: Mandea M, Korte M (eds) Geomagnetic observations and models. IAGA Special Sopron Book Series, vol 5. Springer, Dordrecht

ISO (1993) Guide to the expression of uncertainty in measurement. International Organization for Standardization, Geneva

Jankowski J, Sucksdorff C (1996) Guide for magnetic measurements and observatory practice. IAGA

La Cour D (1930) Le Variomètre de Copenhague, Danske Meteorologiskelnstitut, Communications Magnétiques, Publication No. 11, Copenhague

La Cour D (1936) Le Quartz-Magnetomètre QHM (Quartz Horizontal Force Magnetometer), Danske Meteorologiskelnstitut, Communications Magnétiques etc., Publication No. 15, Copenhague

La Cour D (1942) The Magnetometric. Zero Balance, the BMZ, DanskeMeteorologiskelnstitut, Communications Magnétiques etc., publication No. 19, Copenhague

Lauridsen E (1977) The QHM. Contributions to the theory and practise of the quartz horizontal magnetometer. Danish Meteorological Institute, Geophysical Papers R-50, pp 1-83

Lauridsen E (1981) A quartz declinometer of the classical type. Danish Meteorological Institute, Geophysical papers, R-65, pp 1-27

Laursen V, Olsen J (1971) Classical methods of geomagnetic observations in: encyclopedia of physics III. In: Geophysics, 49/3. Springer, Berlin

Marsal S, Curto JJ (2009) A new approach to the Hourly Mean Computation problem when dealing with missing data. Earth Planets Space 61:945-956. https://doi.org/10.1186/BF03352945

Matzka J, Chulliat A, Mandea M, Finlay CC (2010) Geomagnetic observations for main field studies: from ground to space. Space Si Rev 155:29-64. https://doi.org/10.1007/s11214-010-9693-4

Merveille E (1908) La sección magnética. Traducción del francés por el P. F. Zurbitu, S.J. Barcelona: Gustavo Gili. (Memorias del Observatorio del Ebro; 3)

St. Louis B (2011) INTERMAGNET technical reference manual, version 4.5. http://intermagnet.org/publications/im_manual.pdf. Accessed 5 Mar 2019

Taylor JR (1982) An introduction to error analysis. The study of uncertainties in physical measurements. Oxford University Press, California

Wienert KA (1970) Notes on geomagnetic observatory and survey practice. UNESCO, Brussels

\section{Publisher's Note}

Springer Nature remains neutral with regard to jurisdictional claims in published maps and institutional affiliations.

\section{Submit your manuscript to a SpringerOpen ${ }^{\circ}$ journal and benefit from:}

- Convenient online submission

- Rigorous peer review

- Open access: articles freely available online

- High visibility within the field

- Retaining the copyright to your article

Submit your next manuscript at $\boldsymbol{\nabla}$ springeropen.com 